\title{
ANALISIS KEBUTUHAN SOFT SKILL DALAM MENDUKUNG KARIR ALUMNI AKUNTANSI
}

\section{NEEDS ANALYSIS OF SOFT SKILLS IN SUPPORTING THE CAREER OF ACCOUNTING GRADUATES}

\author{
Oleh: \\ Rr. Indah Mustikawati \\ Staf Pengajar Jurusan Pendidikan Akuntansi Universitas Negeri Yogyakarta \\ rrindahmustikawati@ymail.com \\ Mahendra Adhi Nugroho \\ Staf Pengajar Jurusan Pendidikan Akuntansi Universitas Negeri Yogyakarta \\ mahendra@uny.ac.id \\ Dhyah Setyorini \\ Staf Pengajar Jurusan Pendidikan Akuntansi Universitas Negeri Yogyakarta \\ dhyah_setyorini@uny.ac.id

\section{Amanita Novi Yushita} \\ Staf Pengajar Jurusan Pendidikan Akuntansi Universitas Negeri Yogyakarta \\ amanitanovi@uny.ac.id

\section{Rudi Prasetya Timur} \\ Jurusan Pendidikan Akuntansi Universitas Negeri Yogyakarta \\ rudi.prasetya2015@student.ac.id
}

\begin{abstract}
Abstrak
Kajian Tracer Study ini merupakan penelitian deskriptif evaluatif yang berusaha mendeskripsikan kebutuhan soft skill alumni yang mendukung karier di dunia usaha. Penelitian ini mencoba menganalisis berdasarkan jenis pekerjaan alumni dan posisi alumni serta soft skill yang dimiliki oleh alumni

Penelitian ini dilaksanakan selama 6 bulan, mulai April-Agustus 2016. Adapun tempaat penelitian ini dilakukan di Universitas Negeri Yogyakarta. Variabel penelitian ini adalah Analisis Kebutuhan Soft Skill Dalam Mendukung Karier Alumni Akuntansi yaitu suatu penyelidikan untuk mengetahui peta soft skill yang dimiliki dan kebutuhan soft skill apasaja yang mendukung karier alumni Akuntansi sebenarnya. Populasi penelitian ini adalah mahasiswa alumni Prodi Akuntansi. Adapun sampel penelitian ini adalah mahasiswa angkatan 2004-2014 (lulusan Prodi Akuntansi untuk 10 angkatan, termasuk kelas PKS) yang lulus antara 2009-2016. Data untuk penelitian ini dikumpulkan dengan menggunakan teknik kuesioner (angket) yang didistribusikan kepada populasi penelitian. Penelitian ini akan menggunakan indikator soft skill yang dikembangkan dari Hairi et al (2011) dengan modifikasi skala likert 1-5 menjadi skala 1-7.

Hasil penelitian menunjukkan bahwa Alumni prodi akuntansi telah memiliki kelima skills (Communication Skill, Critical Thinking Skill, Team Work Skill, Program and Project Management Skill dan Decision-Making and Problem Solving Skill). Semua soft skill tersebut sangat penting dalam menunjang karier sehingga harus dimasukan dalam proses pembelajaran dan didukung melalui kegiatan ekstrakurikuler (kegiatan kemahasiswaan). Oleh karena soft skills adalah keterampilan yang bersifat non teknis, invisible, dan unimmediate, maka Softskills tidak dapat diajarkan, tetapi dapat ditularkan dan dipraktikkan berulang-ulang dengan didampingi oleh mentor.
\end{abstract}




\title{
Jurnal Pendidikan Akuntansi Indonesia, Vol. XIV, No. 2, Tahun 2016
}

Rr. Indah Mustikawati, dkk

$13-20$

Kata kunci: Communication Skill, Critical Thinking Skill, Team Work Skill, Program and Project Management Skill dan Decision-Making and Problem Solving Skil

\begin{abstract}
This study was a descriptive study that depict the evaluation of the softskill needs of the alumni in supporting their careers in the corporate world. This study tried to analyze based on the type of work, position as well as soft skills possessed by graduates.

This research was conducted for 6 months, starting from April to August 2016. The study was conducted at the State University of Yogyakarta. The variables of this research was The Analysis of Soft Skill Needs to Support Accounting Careers Alumni. This variable described an investigation to determine who owned the map soft skills and soft skills needs whatever, which supports real Accounting alumni career. The study population was a student alumni of Accounting Department. The sample of this research was the students of 2004-2014 (who graduated of Accounting Department between 10 batches, including a class of PKS) who graduated between 2009-2016. The data were collected by using a questionnaire (questionnaire) which distributed to the study population. This study will use the indicators of developed soft skills of Hairi et al (2011) with a modified Likert scale of 1-5 into 1-7.

The results showed that Prodi Alumni accounting has had five skills (Communication Skills, Critical Thinking Skills, Team Work Skills, Program and Project Management Skills and DecisionMaking and Problem Solving Skill). All the soft skills were very important in supporting the career should be included in the learning process and supported through extracurricular activities (student activities). Therefore soft skills were the skills which were non-technical, invisible, and unimmediate, the soft skills could be not be taught, but it could be transmitted and practiced repeatedly, assisted by a mentor.
\end{abstract}

Keywords: Softskill, Communication Skills, Critical Thinking Skills, Team Work Skills, Program and Project Management Skills and Decision-Making and Problem Solving Skill

\section{PENDAHULUAN}

Pada era pasar bebas ASEAN (MEA) perguruan tinggi dituntut untuk mampu mencetak lulusan yang dapat bersaing dengan lulusan dari berbagai negara. Keberhasilan perguruan tinggi dalam mencetak lulusan yang berkualitas sangat diharapkan agar Indonesia mampu bersaing dengan negara lain. Salah satu aspek keberhasilan pendidikan tinggi adalah aspek relevansi. Dalam aspek relevansi ini, perguruan tinggi dituntut mampu menghasilkan lulusan yang memiliki daya saing dan siap berkiprah di dunia usaha dan dunia industri serta turut mengambil peran dalam pembangunan. Tuntutan karier di dunia kerja saat ini semakin berkembang sehingga berdampak pada keterampilan (skill) yang dibutuhkan untuk mencapai karier yang lebih baik. Ada dua tipe utama skill, yaitu hard skill dan soft skill.

$$
\text { Dewasa ini soft skill yang }
$$
mendominasi kebutuhan di tempat kerja meliputi pengetahuan interpersonal dan intrapersonal, keterampilan dan kemampuan yang berkaitan dengan etika, organisasi personal dan kebiasaan kerja, manajemen waktu, kerja tim dan komunikasi interpersonal, manajemen emosi, kemampuan memecahkan masalah, dan kemampuan dalam belajar (Mc Namara, 2009). Perubahan kebutuhan di tempat kerja tersebut berkaitan dengan perubahan teknologi yang mengubah kebutuhan dunia kerja terhadap keterampilan dari lulusan dari ilmu bisnis (Mitchell, Skinner, \& White, 2010).

Beberapa penelitian telah melakukan penelitian mengenai pentingnya soft skill di tempat kerja. Klaus (2010) menemukan bahwa keberhasilan kerja jangka panjang ditentukan oleh $75 \%$ oleh people skill sedangkan sisanya $25 \%$ ditentukan oleh pengetahuan teknis. Lebih lanjut, Watts \& Watts, (2008) dalam John, (2009) menyatakan soft skill berkontribusi pada 
kesuksesan sebesar $85 \%$ sedangkan hard skill hanya berkontribusi sebesar $15 \%$. Selain itu, pemberi kerja secara progresif mencari pegawai dengan social skill yang bagus, mereka menempatkan soft skill pada tempat yang penting dalam kesuksesan kerja (Wilhelm, 2004).

Rumusan masalah dalam penlitian ini adalah Bagaimana analisis kebutuhan soft skill yang mendukung karier? Tujuan penelitian dari penelitian ini adalah untuk mengidentifikasi dan memetakan soft skill yang dibutuhkan oleh alumni akuntasi dalam mendukung karier di dunia kerja.

\section{Kompetensi Dunia Kerja}

Kebutuhan kompetensi alumni akuntansi untuk memasuki dunia kerja dewasa ini semakin kompleks. Tidak hanya harus memiliki kemampuan teknis, alumni juga harus memiliki kemampuan interpersonal yang baik. Cleary, Flynn dan Thomasson (2006) mendefinisikan keterampilan kerja umum terdiri dari basic / fundamental skills, conceptual / thinking skills, business skill, community skills, people-related skills, dan personal skills.

\section{Peran Soft Skill dalam Karier}

Soft skill didefinisikan sebagai skill interpersonal, skill manusia, people skill atau skill perilaku yang dibutuhkan untuk mengaplikasikan skill teknis dan pengetahuan di tempat kerja (Rainsbury et al , 2002). Soft skill memegang peran yang cukup penting di tempat kerja. Kurangnya soft skill merupakan faktor yang menyebabkan lulusan tidak dapat memperoleh pekerjaan (Hairi et al, 2011). Dalam model recruitment soft skill merupakan salah satu faktor yang dipertimbangkan. Litecky CR, Arnett KP, dan Prabhakar B, (2004) mengambarkan model rekrutmen menggunakan pendekatan dua tahap. Tahap pertama merupakan tahap penyaringan dengan menggunakan kesesuaian hard skill dengan kebutuhan sedangkan pada tahap ke dua mempertimbangkan kesesuaian soft skill dengan persyaratan yang dibutuhkan untuk memutuskan pemilihan pegawai.

\section{Kurikulum dan Soft Skill}

Universitas merupakan lembaga pendidikan yang mempunyai tujuan untuk mempersiapkan lulusan untuk siap terjun di dunia kerja. Kesesuaian materi (kurikulum) dengan kebutuhan dunia kerja merupakan faktor kunci dalam merespons kebutuhan dunia kerja terhadap lulusan. Kebutuhan dunia kerja saat ini tidak sekadar kebutuhan keterampilan teknis (hard skill) tetapi juga kebutuhan terhadap soft skill. Sumner dan Yager, (2008) menyimpulkan bahwa soft skill lebih penting dari pada technical skill bagi lulusan pada program studi Management Information System. Dengan demikian dapat dilihat bahwa kedudukan soft skill dalam kurikulum harus memperoleh porsi yang cukup.

Soft skill gap antara universitas dan dunia kerja seharusnya dapat dipersempit. Cappel (2001) melakukan survei pada pemberi kerja pada soft skill dan hard skill dan ditemukan bahwa gap terbesar ada pada soft skill. Gap tersebut menunjukkan bahwa secara akademis universitas belum mampu memberi bekal yang cukup pada lulusan untuk menghadapi dunia kerja secara jangka panjang.

\section{METODE PENELITIAN}

Kajian Tracer Study ini merupakan penelitian deskriptif evaluatif yang berusaha mendeskripsikan kebutuhan soft skill alumni yang mendukung karier di dunia usaha. Penelitian ini mencoba menganalisis berdasarkan jenis pekerjaan alumni dan posisi alumni serta soft skill yang dimilki oleh alumni. Populasi penelitian ini adalah mahasiswa alumni Prodi Akuntansi. Adapun sampel penelitian ini adalah mahasiswa angkatan 2004-2014 (lulusan Prodi Akuntansi untuk 10 angkatan, termasuk kelas PKS) yang lulus antara 2009-2016. Data untuk penelitian ini dikumpulkan dengan menggunakan teknik kuesioner 
(angket) yang didistribusikan kepada populasi penelitian.

Penelitian evaluasi ini bersifat deskriptif. Semua data yang dikumpulkan melalui angket maupun dokumentasi dianalisis dengan menggunakan teknik analisis deskriptif persentase. Data disajikan dalam bentuk tabel dan gambar untuk melihat kecenderungan kesesuaiannya. Aktivitas dalam analisis data terdiri dari data reduction, data display, dan conclusion drawing / verivication (Sugiyono, 2010). Teknik analisis data yang digunakan dalam penelitian ini adalah analisis data kualitatif yang terdiri dari reduksi data, penyajian data dan penarikan kesimpulan. Untuk mengetahui kecenderungan dari setiap variabel yang diteliti, juga dilakukan analisis tendensi sentral (kecenderungan). Analisis ini bertujuan untuk mengetahui penilaian responden dalam kelompok-kelompok tertentu. Pendekatan yang digunakan adalah pendekatan yang dikembangkan oleh Sutrisno Hadi (2004).

\section{HASIL PENELITIAN PEMBAHASAN \\ Hasil}

Tabel 1. Jumlah Total Responden

\begin{tabular}{|l|r|r|}
\hline Angkatan & Jumlah & Persentase \\
\hline 2006 & 1 & $1 \%$ \\
\hline 2007 & 2 & $1 \%$ \\
\hline 2008 & 9 & $6 \%$ \\
\hline 2009 & 35 & $23 \%$ \\
\hline 2010 & 33 & $22 \%$ \\
\hline 2011 & 32 & $21 \%$ \\
\hline 2012 & 27 & $18 \%$ \\
\hline 2013 & 5 & $3 \%$ \\
\hline 2014 & 9 & $6 \%$ \\
\hline \multicolumn{2}{|c|}{ Sumber: data diolah }
\end{tabular}

Berdasarkan Tabel 1 Jumlah Total Responden, diperoleh 153 responden yang mengisi angket. Dari 153 responden, masing-masing angkatan 2006 dan 2007 menyumbang 1\%. Angkatan 2008 sebanyak 6\%, angkatan 2009 sebanyak 23\% (terbanyak), angkatan 2010 sebanyak 22\%, angkatan 2011 sebanyak 21\%, angkatan 2012 sebanyak 18\%, angkatan 2013 sebanyak 3\%, dan 6\% berasal dari angkatan 2014. Adapun gambar diagramnya dapat dilihat di bawah ini:

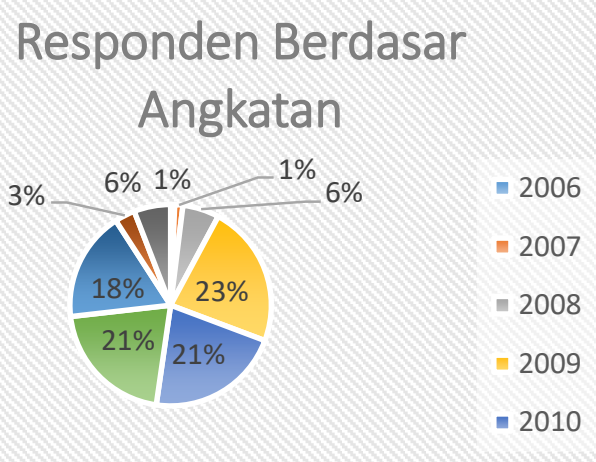

Gambar 1. Diagram Responden Berdasarkan Angkatan

Tabel 2. Pekerjaan Alumni

\begin{tabular}{|l|r|r|}
\hline Pekerjaan & Jumlah & Persentase \\
\hline PNS/TNI/Polri & 12 & $8 \%$ \\
\hline BUMN & 22 & $14 \%$ \\
\hline Swasta & 77 & $50 \%$ \\
\hline $\begin{array}{l}\text { Wiraswasta } \\
\text { (Wirausaha) }\end{array}$ & 11 & $7 \%$ \\
\hline $\begin{array}{l}\text { Mahasiswa } \\
\text { (Melanjutkan }\end{array}$ & & \\
Studi) & 8 & $5 \%$ \\
\hline Belum Bekerja & 23 & $15 \%$ \\
\hline \multicolumn{2}{|c|}{ Sumber: data diolah }
\end{tabular}

Berdasarkan Tabel 2 Pekerjaan Alumni diketahui bahwa 8\% alumni bekerja sebagai PNS/TNI/Polri. Alumni yanag bekerja pada BUMN sebanyak 14\%. Alumni yang bekerja di bidang (perusahaan) swasta sebanyak 50\%. Alumni yang berwirausaha sebanyak 7\%. Alumni yang melanjutkan jenjang pendidikan lebih tinggi ke S2 sebanyak 5\% dan sisanya sebanyak 15\% alumni belum mendapatkan pekerjaan. Gambar diagram pekerjaan alumni dapat dilihat di bawah ini: 


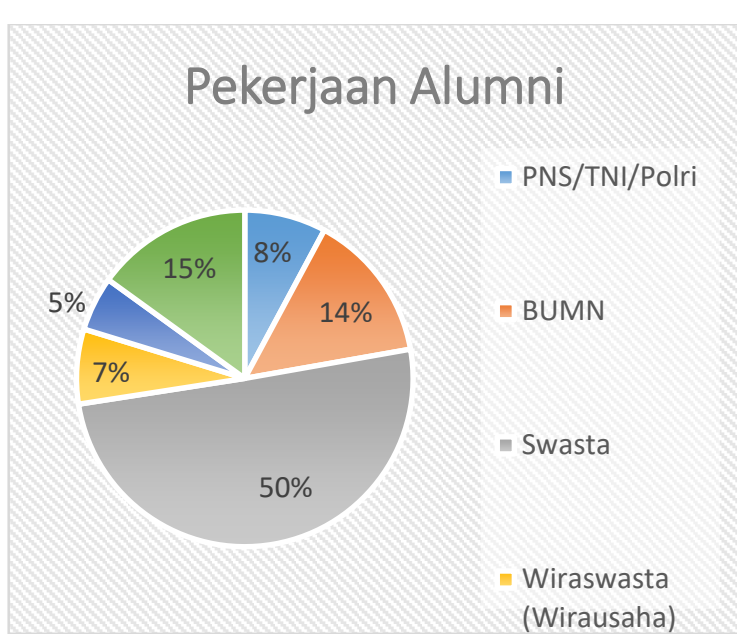

Gambar 2. Pekerjaan Alumni

Tabel 3. Informasi Lainnya

\begin{tabular}{|l|l|}
\hline Lama Studi Rata-rata & 4 th \\
\hline Rerata Gaji Pertama & $\mathrm{Rp} \mathrm{3.416.134,00}$ \\
\hline Rerata skor TOEFL & 434 \\
\hline \multicolumn{2}{|c|}{ Sumber: data diolah }
\end{tabular}

Disamping data mengenai angkatan dan pekerjaan alumni, penelitian ini menunjukkan informasi lainnya yaitu lama studi, rerata gaji pertama, dan rerata skor TOEFL. Rerata lama studi alumni adalah 4 tahun. Adapaun rerata gaji pertamanya sebesar Rp3.416.134,00 dan rerata skor TOEFL alumni sebesar 434.

\section{Pembahasan}

Hasil penelitian Analisis Kebutuhan Soft Skill untuk Menunjang Karir Alumni Prodi Akuntansi menunjukkan bahwa alumni Prodi Akuntansi telah memiliki Communication Skill, Critical Thinking Skill, dan Team Work Skill Sangat Tinggi. Ketiga skill tersebut telah dimiliki oleh semua alumni Prodi Akuntansi. Ketiga skills tersebut mengacu pada skill yang dikelompokkan oleh Schulz (2008) yaitu kualitas pribadi/personal, ketrampilan interpersonal, dan etrampilan tambahan/pengetahuan Untuk Program and Project Management Skill dan DecisionMaking and Problem Solving Skill, meskipun tidak dimiliki semua alumni Prodi Akuntansi (hanya 95\% dan 99\%) tetapi hasilnya masih di atas 90\%. Hal ini menunjukkan bahwa pengembangan softs kills melalui kegiatan kurikuler di Universitas Negeri Yogyakarta, khususnya Prodi Akuntansi telah berhasil dicapai.

Adapun diantara kelima soft skill yang dimiliki oleh alumni (Communication Skill, Critical Thinking Skill, Team Work Skill, Program and Project Management Skill dan Decision-Making and Problem Solving Skill) semuanya memiliki peran penting dalam mengembangkan karier alumni Prodi Akuntansi. Communication Skill dan Team Work Skill merupakan bagian dari people related skill. Kedua keterampilan tersebut berkaitan dengan kualitas interpersonal seseorang dalam berkomunikasi dan bekerja sama dalam tim. Dengan kedua ketrampilan yang sangat baik tersebut maka Basic/fundamental skills berkaitan dengan keterampilan teknis dan pengetahuan mengenai tugas (yaitu Program and Project Management Skill dan Decision-Making and Problem Solving Skill) juga akan baik. Program and Project Management Skill dan Decision-Making and Problem Solving Skill merupakan keterampilan dasar yang harus dimiliki oleh pekerja. Kedua ketrampilan tersebut termasuk dalam kategori Conceptual/ thinking skill yang berkaitan dengan kemampuan untuk perencanaan, mengumpulkan dan mengorganisasi informasi serta kemampuan untuk memecahkan masalah. Kemampuan merencanakan, mengumpulkan dan mengorganisasi informasi serta kemampuan untuk memecahkan masalah akan baik bila didasari dengan kemampuan berkomunikasi dan bekerjasama dalam tim. Hasil penelitian ini menudukung penelitian Mc. Namara (2009) bahwa soft skill yang mendominasi kebutuhan di tempat kerja meliputi pengetahuan interpersonal dan intrapersonal, keterampilan dan kemampuan yang berkaitan dengan etika, organisasi personal dan kebiasaan kerja, manajemen waktu, kerja tim dan komunikasi interpersonal, manajemen emosi, kemampuan memecahkan masalah, dan 
kemampuan dalam belajar (Mc Namara, 2009).

\section{SIMPULAN DAN SARAN \\ Simpulan}

Berdasarkan hasil penelitian di atas dapat disimpulkan bahwa Alumni prodi akuntansi telah memiliki kelima skills (Communication Skill, Critical Thinking Skill, Team Work Skill, Program and Project Management Skill dan DecisionMaking and Problem Solving Skill). Semua soft skill tersebut sangat penting dalam menunjang karier.

\section{Saran}

1. Oleh karena kelima soft skill skills (Communication Skill, Critical Thinking Skill, Team Work Skill, Program and Project Management Skill dan Decision-Making and Problem Solving Skill) tersebut sangat penting maka harus dimasukan dalam proses pembelajaran dan didukung melalui kegiatan ekstrakurikuler (kegiatan kemahasiswaan

2. Oleh karena soft skills adalah keterampilan yang bersifat non teknis, invisible, dan unimmediate, maka Softskills tidak dapat diajarkan, tetapi dapat ditularkan. Dengan demikian kegiatan pengembangan soft skills tidak akan optimal bila hanya berhenti pada pelatihan, seminar dan workshop. Pengembangan soft skills harus dipraktikkan berulang-ulang dan didampingi oleh mentor (Illah Sailah, 2008). Dengan kata lain kegiatan harus terencana, terprogram dan tersistem serta didampingi coach atau mentornya yang membimbing kemana arah kegiatan tersebut akan dilaksanakan.

\section{DAFTAR PUSTAKA}

Ashton, F. (1994). The other managers competencies. Training Officer, 30(1), $15-16$.

Cappel, J. J. (2001), Entry-Level IS Job Skills: A Survey of Employers,
Journal of Computer Information Systems, Vol. 42, No. 2, pp. 76-82.

Caudron, S. (1999). The hard case for soft skills. Workforce, 78(7), 60-64.

Cleary, M., Flynn, R., \& Thomasson, S. (2006). Employability skills from framework to practice: An introductory guide for trainers and assessors. Canberra, Australia: Department of Education, Science and Training

Cohen, M.G. (ed.) (2003) Training the Excluded for Work. Vancouver and Toronto: UBC Press.

Fang, X., Lee, S., and Koh, S. (2005) Transition of Knowledge/Skills Requirement for Entry-Level IS Professionals: An Exploratory Study Based on Recruiters' Perception, Journal of Computer Information Systems, Vol. 46, No. 1, pp. 58-70.

Georges, J.C. (1996). The myth of soft skills training. Training, 33(1), 48.

Golding, P., Tennant, V., and Donaldson, O. (2008), An empirical classification of employability skills for entry level IS/IT Professionals, Paper presented at the AIS SIGED IAIM Conference, Paris, France.

Goles, T., Hawk, S., and Kaiser, K. M. (2008), Information Technology Workforce Skills: The Software and IT Services Provider Perspective, Information Systems Frontiers, Vol. 10, No. 2, pp. 179-194.

Green, G.L. (1989), Perceived Importance of Systems Analysis Job Skills, Roles, and Non-salary Incentives, MIS Quarterly, 13:2, pp. 115-133.

Gupta, J. N. D., Wang, P., and Ravichandran, R. (1994), An Assessment of Information Systems Education Needs in Taiwan, International Journal of Information Management, Vol. 14, No. 5, pp. 369384.

Hairi, A. F. B., Toee, B.M.N.B.A. and Razzaly, C.W.B. (2011), Employers' Perception on Soft Skills of 
Graduates: A Study of Intel Elite Soft Skill Training, International Conference on Teaching \& Learning in Higher Education (ICTLHE 2011).

Huang, H., Kvasney, L., Joshi, K. D., Trauth, E., and Mahar, J. (2009), Synthesizing IT Job Skills Identified in Academic Studies, Practitioner Publications and Job Ads," Paper presented at the SIGMIS Conference on Computer Personnel Research, Limerick, Ireland.

Illah Sailah.2008. Pengembangan Soft Skills Di Perguruan Tinggi. Jakarta : Direktorat Jenderal Pendidikan Tinggi

Janicki, T. N., Lenox, T. L., Logan, R., and Woratscheck, C. R. (2008), Information Systems/Technology Employer Needs Survey: Analysis by Curriculum Topic, Information Systems Education Journal, Vol. 6, No. 18 , pp.

John, J. (2009). Study on the nature of impact of soft skills training programme on the soft skills development of management students. Pacific Business Review, October/December, 19-27.

Klaus, P. (2010). Communication breakdown. California Job Journal, 28, 1-9.

Koppi, T., Sheard, J., Naghdy, F., Chicharo, J., Edwards, S. L., Brookes, W., and Wilson, D. (2009), What Our ICT Graduates Really Need from Us: A Perspective from the Workplace, Paper presented at the Eleventh Australasian Conference on Computing Education, Darlinghurst, Australia.

Lafer, G. (2004) 'What Is Skill?', in C. Warhurst et al. (eds) The Skills That Matter, pp. 109-27. Basingstoke: Palgrave Macmillan.

Lee, C. K., and Han, H.-J. (2008), Analysis of Skills Requirement for Entry-Level Programmer/Analysts in Fortune 500 Corporations, Journal of Information
Systems Education, Vol. 19, No. 1, pp. 17-27.

Lee, S. M., and Lee, C. K. (2006), IT Manager's Requisite Skills, Communications of the ACM, Vol. 49, No. 4, pp. 111-115.

Lee, S., Koh, S., Yen, D., and Tang, H.-L. (2002), Perception Gaps Between IS Academics and IS Practitioners: An Exploratory Study, Information and Management, Vol. 40, No. 1, pp. 5161.

Leitheiser, R.L. (1992), MIS Skills for the 1990s: A Survey of MIS Managers' Perceptions, Journal of Management Information Systems, 9:1, Summer, pp. 69-91.

Litecky CR, Arnett KP, dan Prabhakar B, (2004), The Paradox of Soft Skills Versus Technical Skills in IS Hiring, Journal of Computer Information Systems, Fall pp 69-76

Mc Namara, B.R. (2009), The Skill Gap: Will the Future Workspace Become an Abyss, Techniques. May.

McMurtrey, M. E., Downey, J. P., Zeltmann, S. M., and Friedman, W. H. (2008), Critical Skill Sets of EntryLevel IT Professionals: An Empirical Examination of Perceptions from Field Personnel, Journal of Information Technology Education, Vol. 7, pp. 101-120.

Merhout, J. W., Havelka, D., and Hick, S. N. (2009), Soft Skills versus Technical Skills: Finding the Right Balance for an IS Curriculum, Paper presented at the Americas Conference on Information Systems, San Francisco, California.

Mitchell, G. W., Skinner, L. B., \& White, B. J. (2010). Essential soft skills for success in the twenty-first century workforce as perceived by business educators. Delta Pi Epsilon Journal, 52, 43-53.

Mullen, J. (1997). Graduates deficient in soft skills. People Management, November 6, 18. 
Noll, C. L., and Wilkins, M. (2002), Critical Skills of IS Professionals: A Model for Curriculum Development, Journal of Information Technology Education, Vol. 1, No. 3, pp. 143-154.

Payne, J. (1999) All Things to All People: Changing Perceptions of 'Skill' among Britain's Policymakers since the 1950s and Their Implications. SKOPE Research Paper No. 1. Oxford and Coventry: Oxford and Warwick Universities.

Payne, J. (2000) 'The Unbearable Lightness of Skill: The Changing Meaning of Skill in UK Policy Discourses and Some Implications for Education and Training', Journal of Education Policy 15(3): 353-69.

Rainsbury, E., Hodges, D. , Burchell, N. and Lay, M. (2002) Ranking workplace competencies: Student and graduate perceptions, Asia-Pacific Journal of Cooperative Education 3 (2) : 8 - 18 .

Richards, T., Yellen, R., Kappelman, L., and Guynes, S. (1998), Information Systems Manager's Perceptions of IS Job Skills, The Journal of Computer Information Systems, Vol. 38, No. 3, pp. 53-57.

Robles, M.M, (2012), Executive Perceptions of The Top 10 Soft Skills Needed in Today's Workplace, Business Communication Quarterly 75(4) 453465.

Schulz, B., (2008), The Importance of Soft Skills: Education Beyond Academic
Knowledge, Journal of Language and Communication, June .

Shibata, H. (2001) 'Productivity and Skill at a Japanese Transplant and its Parent Company', Work and Occupations 28(2): 234-60.

Strebler, M. (1997). Soft skills and hard questions. People Management, 3(11), 20-24.

Sugiyono. (2010).Statistik untuk Penelitian.Bandung: CV Alfabeta.

Sumner, M., and Yager, S. E. (2008) "An Investigation of Preparedness and Importance of MIS Competencies: Research in Progress," Paper presented at the ACM SIGMIS CPR Conference on Computer Personnel doctoral consort ium and research, Charlottesville, Virginia, pp. 97-100.

Sutrisno Hadi (2004), Analisis Regresi, Fakultas psikologi UGM , Yogyakarta.

Trauth, E.M., D.W. Farwell and D. Lee. (1993) The IS Expectation Gap: Industry Expectations versus Academic Preparation, MIS Quarterly, 17:3, September, pp. 293-307.

Wilhelm, W. J. (2004). Determinants of moral reasoning: Academic factors, gender, richness of life experiences, and religious preferences. Delta $\mathrm{Pi}$ Epsilon Journal, 46, 105-121.

Wilkerson, J.W, (2012), An Alumni Assessment of MIS Related Job Skill Importance and Skill Gaps, Journal of Information Systems Education, Vol. 23(1) 